\title{
A RELAÇÃO DE LIMPEZA URBANA E QUALIDADE AMBIENTAL: UM ESTUDO SOBRE AS CONDIÇÕES DE LIMPEZA URBANA NO BAIRRO NOVA ITUIUTABA I, NA CIDADE DE ITUIUTABA/MG
}

\author{
Jéssica Oliveira Barbosa \\ Universidade Federal de Uberlândia, Instituto de Ciências Humanas \\ Programa de Pós-Graduação em Geografia do Pontal, Ituiutaba, MG, Brasil \\ jessica oliveirabarbosa09@yahoo.com.br \\ Gerusa Gonçalves Moura \\ Universidade Federal de Uberlândia, Instituto de Ciências Humanas - \\ Programa de Pós-Graduação em Geografia do Pontal, Ituiutaba, MG, Brasil \\ gerusaufu@gmail.com
}

\section{RESUMO}

O serviço de limpeza urbana é essencial para garantir à população condições mínimas de salubridade e auxilia na manutenção da qualidade ambiental. No entanto, mesmo considerando a sua importância, a discussão sobre limpeza urbana ainda é muito recente, principalmente ao entendê-la relacionada ao debate da qualidade ambiental. Portanto, o objetivo deste artigo é apresentar a limpeza urbana enquanto indicador da qualidade ambiental, a partir da avaliação das condições de limpeza urbana no bairro Nova Ituiutaba I, localizado na cidade de Ituiutaba/MG, constituído por residências do Programa Minha Casa Minha Vida (PMCMV). Para a elaboração deste trabalho foram adotados os seguintes procedimentos metodológicos: i) Levantamento bibliográfico, ii) Visita preliminar em campo para a elaboração do roteiro de observação e a sistematização da ordem das ruas a serem percorridas; iii) Elaboração de roteiro de observação; iv) Monitoramento da área de estudo; v) Sistematização dos dados e análise dos resultados obtidos. Os resultados foram organizados em quadros e tabelas e apresentam uma grande variedade de tipos de resíduos descartados. A partir das observações realizadas nos monitoramentos, notou-se a precariedade do serviço de limpeza urbana e os riscos ambientais e de saúde existentes em decorrência do descarte inadequado de resíduos

Palavras-chave: Limpeza urbana. Qualidade ambiental. Monitoramento. Resíduos.

\begin{abstract}
The urban cleaning service is essential to guarantee the population minimum health conditions and assists in the maintenance of environmental quality. However, even considering its importance, the discussion about urban cleaning is still very recent, especially when it is related to the debate on environmental quality. Therefore, the objective of this article is to present the urban cleaning as an indicator of environmental quality, based on the evaluation of the urban cleaning conditions in the Nova Ituiutaba I neighborhood, located in the city of Ituiutaba/MG, constituted by residences of the "Programa Minha Casa Minha Vida"(PMCMV). For the preparation of this work, the following methodological procedures were adopted: i) Bibliographical survey; ii) Preliminary field visit for the elaboration of the observation route and the systematization of the order of the streets to be covered; iii) Elaboration of observation itinerary; iv) Monitoring of the study area; v) Systematization of the data and analysis of the results obtained. The results were organized in tables and tables and present a wide variety of waste types discarded. From the observations made in the monitoring, it was noted the precariousness of the urban cleaning service and the existing environmental and health risks due to the inadequate waste disposal.
\end{abstract}

Keywords: Urban cleaning. Environmental quality. Monitoring. Residues. 


\section{INTRODUÇÃO}

As condições de vida nas cidades trata-se de um tema frequente na Geografia e, devido a sua diversidade social, econômica e cultural, apresenta diversos estudos e pesquisas no âmbito da Geografia Urbana. O crescimento das cidades, muitas vezes desordenado, gera desigualdades sociais e problemas ambientais que comprometem a segurança e a saúde da população. Frente a este contexto, um dos exercícios das pesquisas e estudos em Geografia Urbana é o de compreender os principais problemas que assolam o viver nas cidades, as transformações que o modo de vida urbana causa no ambiente e buscar medidas que proporcionem melhorias na qualidade ambiental e de vida.

Um dos serviços urbanos que possui ampla possibilidade de diálogo teórico-metodológico nos estudos de Geografia Urbana é o de limpeza urbana. Trata-se de um tipo de serviço urbano que tem como propósito manter as áreas públicas limpas e reduzir os problemas ligados ao descarte inadequado de resíduos sólidos (sejam estes domiciliares ou aqueles oriundos da construção civil, de atividades econômicas ou industriais), tais como o entupimento de sistemas de coleta de águas pluviais, incidência de insetos vetores de doenças e animais peçonhentos, mau cheiro, dentre outros. Portanto, além da função de "embelezamento", morar em uma cidade limpa nos permite viver em um lugar agradável e mais saudável.

É possível relacionar também o papel da limpeza urbana com outra discussão muito relevante e cada vez mais presente nos estudos geográficos urbanos, que é a qualidade ambiental. De modo introdutório, qualidade ambiental pode ser compreendida como um conjunto de condicionantes que vão garantir a existência de um ambiente equilibrado, isto é, que não coloque em risco as espécies da fauna, flora, qualidade do ar e das propriedades químicas e físicas do solo, de modo que seja possível que o homem possa viver de forma saudável e sem esgotar ou colocar em risco os recursos naturais (BARBOSA, J.O, 2018).

Falar em qualidade ambiental, portanto, significa conciliar o modo de viver do homem na cidade com a gestão dos recursos naturais, de modo a permitir a vida de forma saudável tanto para a sociedade quanto para os sistemas naturais. Frente disto, se os serviços de limpeza urbana são realizados de forma eficaz e periódica, consequentemente estes poderão contribuir significativamente para a melhoria das condições de qualidade ambiental nas cidades.

Portanto, o objetivo principal deste trabalho, resultante de uma pesquisa de mestrado em Geografia realizada entre os anos de 2017 e 2018, é conhecer as condições de limpeza urbana no bairro Nova Ituiutaba I, localizado na cidade de Ituiutaba/MG. A fim de responder questões mais secundárias, os objetivos específicos que norteiam este trabalho são: i) identificar as condições de limpeza dos espaços públicos do Bairro Nova Ituiutaba I, como as ruas e lotes vazios; ii) analisar os tipos e resíduos encontrados ao longo das vias públicas, caminhos (calçadas) e bueiros; iii) avaliar a limpeza urbana enquanto um indicador da qualidade ambiental no bairro Nova Ituiutaba I.

Este conjunto habitacional foi escolhido enquanto objeto de estudo pelo fato de ser um dos conjuntos habitacionais mais recentemente ocupados na cidade de Ituiutaba/MG e que, apesar dos domicílios serem entregues com lixeiras, foi possível identificar o descarte inadequado de resíduos nas ruas e lotes vazios. Além disso, alguns profissionais da área de Serviço Social, que trabalharam em projetos de integração social com a população residente no bairro, reconheceram a necessidade de haver oficinas de educação ambiental que fossem permanentes, no sentido de incentivar a limpeza e o cuidado com o "bairro", para evitar problemas ambientais e de saúde para a população local.

Outro aspecto relevante que embasou a escolha desta área de estudo é que existe uma legislação que orienta a construção das habitações do Programa Habitacional Minha Casa Minha Vida, a qual destaca a importância das condições ambientais necessárias para o bem-estar da população. Todavia, os problemas ambientais existentes distancia muitos conjuntos habitacionais de interesses sociais das condições ideais de moradia, e esta situação se repete no bairro Nova Ituiutaba I.

O bairro Nova Ituiutaba I iniciou suas obras em 2013. Nele foi construído o total de 529 residências pela empresa PDCA Engenharia (FERREIRA, 2016) e entregues aos moradores em dezembro de 2015. De acordo com Ferreira (2016), a cidade possui 75 bairros, nos quais, 16 são bairros criados a partir dos conjuntos habitacionais do PMCMV. O bairro contemplado nesta pesquisa (Nova Ituiutaba

$\begin{array}{llllll}\text { Caminhos de Geografia } & \text { Uberlândia - MG } & \text { v. 21, n. } 73 & \text { Mar/2020 } & \text { p. 399-414 Página } 400\end{array}$


I) é o maior construído (Figura 1), se comparado com os demais existentes na mesma área (Nova Ituiutaba II, III e IV).

Figura 1 - Ituiutaba/MG: localização do bairro Nova Ituiutaba I, 2018.

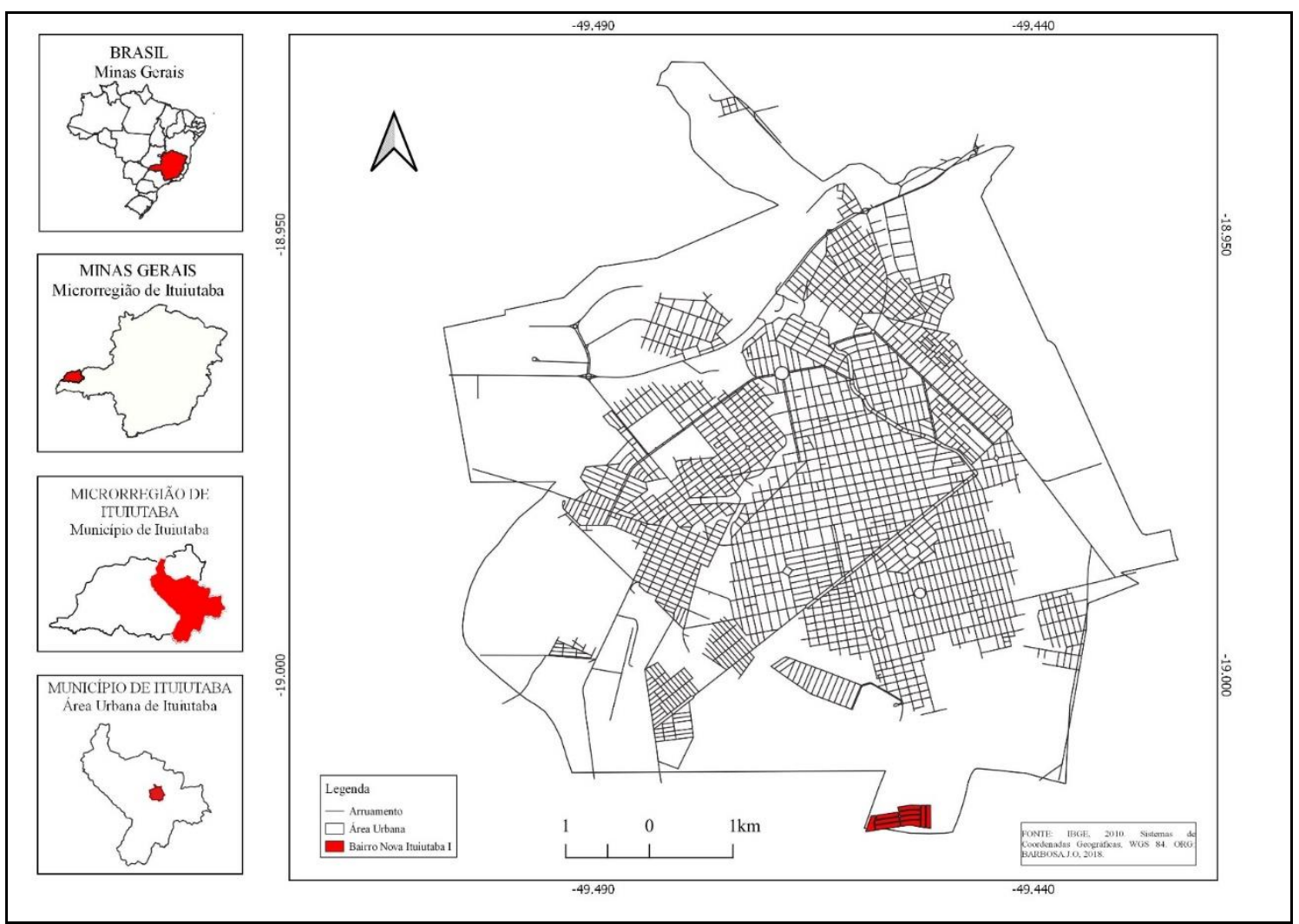

Fonte: AUTOR, 2018.

Foram realizadas algumas visitas ao bairro Nova Ituiutaba I para analisar de que maneira os serviços de limpeza urbana eram feitos e, de acordo com os tipos de materiais encontrados, identificar a sua periodicidade. Foi notado que ocorria o depósito de resíduos em locais inapropriados (em lotes vazios e ruas) e que se tratava de uma situação muito semelhante a que se encontra em bairros oriundos de programas de habitação social construídos na cidade a mais tempo

O contexto da limpeza urbana no bairro Nova Ituiutaba I colocou-se como um problema que provocou uma série de questões, tais como: Por que há tanta sujeira neste bairro? Seria resultado da falta ou precariedade do serviço de coleta de lixo? Ou se trata também de um problema relacionado à falta de educação ambiental? Com que frequência este bairro era atendido pelo serviço de limpeza urbana? Se, em menos de um ano este bairro já apresenta descarte de resíduos em locais inapropriados, qual será a proporção destes resíduos daqui cinco ou dez anos? Em que medida este descarte inadequado pode comprometer a qualidade ambiental deste bairro?

Com base nestas constatações foram realizadas pesquisas iniciais que pudessem dar o aporte teórico necessário para compreender a relação entre qualidade ambiental, descarte de resíduos sólidos domiciliares e limpeza urbana. Observou-se que, apesar da infinidade de trabalhos analisando os conjuntos habitacionais do PMCMV, são poucas as pesquisas realizadas com base nestes temas. Desta forma, foi justamente a falta de trabalhos sobre esta abordagem que despertou o interesse em estudar, a princípio, a questão dos resíduos sólidos e sua relação com a qualidade ambiental, como é apresentado, ainda que de modo introdutório, em Nucci (2008).

$\begin{array}{llllll}\text { Caminhos de Geografia } & \text { Uberlândia - MG } & \text { v. 21, n. 73 } & \text { Mar/2020 } & \text { p. 399-414 } & \text { Página } 401\end{array}$


É preciso salientar que, no processo de elaboração de uma pesquisa científica é necessário valer-se de procedimentos que permitam a coleta dos dados e informações almejadas, além de garantir a validade de tudo o que foi pesquisado. Frente a esse contexto, Andrade (2010) e Demo (1995) concordam com a concepção de que a metodologia deve ser entendida como o campo da ciência que se dedica aos caminhos e instrumentos utilizados para se produzir um estudo científico, valendo-se, muitas vezes, de diferentes procedimentos metodológicos e de métodos específicos.

Para a realização deste trabalho, portanto, o primeiro procedimento metodológico adotado foi o levantamento bibliográfico e realização de leituras acerca dos temas que seriam abordados. Esta etapa é a mais importante de todas, pois só é possível investigar um determinado processo se, primeiramente, se estiver claro quais os objetivos da pesquisa, mesmo que estes sejam alterados ao longo de seu desenvolvimento.

Apesar da relevância da discussão, na Geografia não foram encontrados trabalhos que apresentem a limpeza urbana enquanto política pública ou instrumento de melhoria da qualidade de vida e ambiental da população. Todavia, grande parte do acervo teórico geográfico encontrado discute, com bastante pertinência, o papel do descarte inadequado de resíduos sólidos urbanos na precarização da qualidade ambiental.

Outro problema encontrado, ainda na etapa da realização das leituras, refere-se a dificuldade de relacionar a discussão da qualidade ambiental com a limpeza urbana. Apesar de estar presente em alguns trabalhos, tais como os de Lima $(2009,2013)$, Ferreira (2016), Nucci (2008), apenas para citar alguns exemplos, a discussão sobre qualidade ambiental e limpeza urbana ainda se encontra no âmbito da existência da coleta e manejo de resíduos sólidos urbanos em aterros sanitários e lixões.

Perante este contexto, buscou-se extrair alguns aspectos apresentados nestes trabalhos citados acima que estivessem relacionados, de forma transversal, à temática deste trabalho e enxergar, a partir de debates e análises, de qual forma a limpeza urbana pode ser inserida no debate sobre qualidade ambiental dentro do contexto urbano.

Neste mesmo momento foram realizadas leituras que abordassem as legislações que tratavam sobre a limpeza urbana em escala nacional, como é o caso das leis e resoluções de órgãos nacionais ambientais, e àquelas que abordassem as exigências do bairro PMCMV sobre as questões ambientais que envolvessem a limpeza urbana. Posteriormente, realizaram-se algumas pesquisas sobre as políticas públicas existentes no município de Ituiutaba a respeito da limpeza urbana.

Nesta etapa da pesquisa foram consultados alguns documentos como o Plano Diretor Municipal, algumas leis/decretos e também projetos de leis e legislações implantadas em outros municípios, como forma de entender como a limpeza urbana poderia ser tratada no município de Ituiutaba (e, neste estudo em especial, no bairro Nova Ituiutaba I). O intuito destas leituras foi compreender em que medida as legislações municipais estão sendo cumpridas e se a limpeza urbana é vista ou entendida enquanto um dos instrumentos da política municipal ambiental e de saneamento e quais seriam as possíveis penalidades para aqueles que contrariassem a legislação vigente.

Partindo destes pressupostos, optou-se por dar prosseguimento à segunda etapa das leituras, que foram realizadas no intuito de buscar trabalhos que discorressem sobre procedimentos metodológicos que pudessem auxiliar o processo de elaboração dos instrumentos para esta pesquisa. Neste contexto, os trabalhos de Nucci (2008), Ferreira (2016), Reis e Ferreira (2008) e o Índice de Sustentabilidade (2014) foram relevantes para se pensar quais os instrumentos ou procedimentos deveriam nortear a coleta dos dados. Todas estas leituras contribuíram para a elaboração do referencial teórico e para a reestruturação do objeto de pesquisa, objetivos e metodologia. Foi com base nestas leituras que se buscaram procedimentos que nos orientassem na forma e no conteúdo a ser pesquisado.

Entretanto, mesmo diante das diferentes abordagens metodológicas realizadas pelos autores aqui citados, nenhuma destas mostrou-se suficiente para que os objetivos desta pesquisa fossem alcançados. De tal forma, encontrou-se o desafio de utilizarmos alguns dos procedimentos metodológicos propostos por Nucci (2008), mas também optamos por utilizarmos procedimentos metodológicos específicos em nossa metodologia para a verificação das condições de limpeza urbana para o local de estudo desta pesquisa.

$\begin{array}{llllll}\text { Caminhos de Geografia } & \text { Uberlândia - MG } & \text { v. 21, n. } 73 & \text { Mar/2020 } & \text { p. 399-414 Página } 402\end{array}$


Antes de partir para a realização do monitoramento, foi realizado a primeira visita de campo, de modo a reconhecer a área de estudo e entender como a ausência de limpeza pública transforma a paisagem e, principalmente, a situação da limpeza urbana neste bairro. Após esta primeira visita, foi identificada a necessidade de se criar um instrumento que orientasse a coleta de campo e, neste sentido, esboçou-se um roteiro preliminar que pudesse, além de nortear o monitoramento, explorar a área de estudo e identificar novos elementos.

Para a realização do roteiro de observação foi necessário realizar outra visita ao campo, na qual foram percorridas nove ruas do total de onze existentes no bairro, desta vez no intuito de identificar quais os tipos de resíduos encontrados nas calçadas, ruas, sarjetas, lotes vazios e bueiros. Após esta etapa, partimos para a reestruturação do modelo do roteiro (Apêndice 1), ampliando as espécies de resíduos que poderiam vir a ser encontradas na realização do monitoramento. Antes de aplicá-lo, foi realizado um pré-teste, com o objetivo de identificar se o instrumento criado necessitava de ajustes e se atenderia aos objetivos estabelecidos.

Nesta versão do roteiro, a organização das variáveis obedeceu a seguinte ordem: tipos de resíduos encontrados nas calçadas, nas sarjetas e nos lotes vazios. As informações secundárias para a pesquisa (tais como existência e frequência de coleta de resíduos domiciliares e coleta seletiva) poderiam ser confirmadas com alguns moradores, dispensando a aplicação de questionários.

O principal procedimento metodológico para avaliação das condições de limpeza urbana foi o monitoramento do bairro a partir da observação dos tipos de resíduos encontrados nas calçadas, sarjetas e lotes vazios. O monitoramento foi realizado ao longo de um ano e dividido em três etapas: monitoramento entre os meses de setembro a dezembro de 2017 e entre os meses de fevereiro e março, maio e junho de 2018. Ao terminar cada ciclo de coleta de informações em campo, os dados foram sistematizados em tabelas e, ao final da última etapa do campo, a análise dos resultados foi realizada a partir da elaboração de gráficos.

Além disso, os resultados também foram reorganizados em categorias, de modo a facilitar a representação dos dados e das informações coletadas. Para representar a localização do bairro, as ruas percorridas, a existência de bueiros e de lotes vazios utilizados para descarte, além da representação do percentual de lixeiras no bairro, os dados foram representados a partir de mapas, realizados no programa Quantum Gis versão 3.2.

\section{RESULTADOS E DISCUSSÃO}

Se os debates sobre a limpeza urbana ainda são poucos, o conceito de qualidade ambiental ainda é bastante recente, mesmo com a sua relevância tanto no campo teórico quanto metodológico da Geografia, principalmente nos estudos urbanos de avaliação de impactos ambientais. Apesar deste cenário, diversas ciências têm realizado estudos que relacionam a qualidade ambiental a aspectos ligados às áreas verdes, qualidade da água, ar, saúde pública e vida urbana. Lima (2013, p. 49) nos traz uma abordagem inicial a respeito do que se compreende por qualidade ambiental, ao explicar que

[...] considerando que "qualidade" significa "propriedade, atributo ou condição das coisas ou das pessoas", pode-se dizer que a qualidade ambiental se refere ao padrão a ser estabelecido e/ou alcançado de satisfação ambiental. Considerada então, como um fator que pode indicar o grau de comprometimento ambiental, referindo-se à associação dos fatores ecológicos e socioeconômicos.

Neste sentido, a qualidade ambiental trata-se de um elemento que garante a reprodução da sociedade de forma saudável e harmoniosa, afinal, "[...] o acesso a um meio ambiente ecologicamente equilibrado emerge como um direito coletivo e se baseia na ideia de interesse comum. Ações devem ser praticadas para a convivência harmônica com a natureza". (MINAKI, 2014, p. 44). Com isso, a qualidade ambiental pode ser entendida como um instrumento que permite justamente mensurar e avaliar as condições ambientais existentes nas cidades, na busca de assegurar o convívio harmonioso e sustentável entre homem e natureza.

Este conceito é também muito amplo e complexo, como aponta Minaki (2014), tanto metodologicamente quanto no que se refere à discussão teórica acerca de sua conceituação ou entendê-la enquanto categoria de análise. De qualquer forma, a discussão sobre qualidade ambiental oferece grandes contribuições para os estudos e pesquisas de cunho geográfico, devido aos

$\begin{array}{llllll}\text { Caminhos de Geografia } & \text { Uberlândia - MG } & \text { v. 21, n. 73 } & \text { Mar/2020 } & \text { p. 399-414 } & \text { Página } 403\end{array}$


inúmeros elementos e temas que o envolvem, cooperando significativamente na avaliação de espaços que possam proporcionar maior conforto para a sociedade e, concomitantemente, gerar o mínimo possível de impactos ambientais.

Destaca-se, neste contexto, a importância da limpeza urbana no saneamento básico para a qualidade ambiental e de vida nas cidades, pois garante a existência de um ambiente limpo, com menor probabilidade de se tornar lócus de vetores de doenças, habitat de insetos e animais peçonhentos, além de proporcionar maior conforto e bem-estar para a população. Godoy (2015, p. 18) ressalta a importância da limpeza urbana ao explicar que se trata de

[...] um conjunto de atividades essenciais ao funcionamento da cidade, por uma série motivos de segurança e saúde pública - coletar o lixo e destiná-lo corretamente evita a proliferação de vetores e doenças e aumenta a segurança nas vias públicas ao evitar que objetos fiquem deixados pelo caminho, bem como promove o bem-estar ao evitar elementos desagradáveis no espaço público

A limpeza urbana, portanto, pode ser entendida como uma das ferramentas essenciais para o saneamento básico, garantindo o controle do conforto, equilíbrio e qualidade ambiental. Para compreender melhor o que é a limpeza urbana e aonde a mesma se aplica, temos a definição apresentada pela Pesquisa Nacional de Saneamento Básico (IBGE, 2008, p. 28), que explica que limpeza urbana envolve um

[...] conjunto de serviços destinados a promover a limpeza de vias públicas e logradouros públicos, pavimentados ou não, tais como: varrição manual ou mecânica; capina e/ou roçada; raspagem de terra e outros resíduos carreados para as vias e/ou logradouros por causas naturais, como chuvas, ventos, enchentes etc.; limpeza de bueiros; limpeza de praias marítimas, fluviais ou lacustres; poda de arborização pública; lavação das ruas; ou outras atividades complementares, como, por exemplo, pintura de meios -fios, limpeza de monumentos, e retirada de faixas e cartazes colocados em locais públicos de forma irregular.

A discussão destes conceitos permitiu compreender as condições de limpeza urbana e seus impactos na qualidade ambiental no bairro Nova Ituiutaba I. Este encontra-se localizado na porção sul da área urbana da cidade, formado por residências financiadas pelo Programa Minha Casa Minha Vida. A caracterização do bairro foi elaborada a partir de visitas antes da realização deste estudo e também de consultas e levantamento de documentos disponibilizados pela Secretaria Municipal de Planejamento e Meio Ambiente e Secretaria Municipal de Desenvolvimento Social.

Este bairro surgiu em 2013, a partir da construção das moradias de interesse social, o que faz com que comumente seja denominado como "conjunto habitacional". Por isso, antes de abordar os resultados faz-se necessário esclarecer um posicionamento metodológico acerca do conceito de bairro utilizado nesta pesquisa. O loteamento Nova Ituiutaba I é denominado "Bairro Nova Ituiutaba I", conforme o decreto n. 7.099, de 15 março de 2012.

O bairro não possui alguns equipamentos sociais que contribuiriam para melhorar as condições de vida da população: não há escola ou creche, apesar de estar há três quilômetros da Universidade Federal de Uberlândia (Campus Pontal) e da Escola Municipal Rosa Tahan (ensino infantil e fundamental - integral). Sobre os serviços de saúde, a população é atendida pelo Posto de Saúde Familiar (PSF) do bairro Tupã, também há três quilômetros de distância. Porém, o bairro não é atendido por postos de policiamento, praças ou biblioteca pública.

Sobre a estrutura comercial, o bairro possui apenas estabelecimentos comerciais voltados para o segmento alimentício, como conveniências, bares e lanchonete e não há opções de lazer privado. Há uma quadra de vôlei e futebol, porém, não é coberta e não há arquibancada ou banheiros públicos. $O$ bairro também não possui parques, jardins ou áreas verdes, e as casas não foram entregues com árvores ou manilha específica para o cultivo de árvore; as casas possuem apenas um calçamento no modelo caminho e o restante da área de calçamento não é gramada

$\begin{array}{llllll}\text { Caminhos de Geografia } & \text { Uberlândia - MG } & \text { v. 21, n. } 73 & \text { Mar/2020 } & \text { p. 399-414 Página } 404\end{array}$


Figura 2 - Ituiutaba/MG: entrada do bairro Nova Ituiutaba I, 2018.

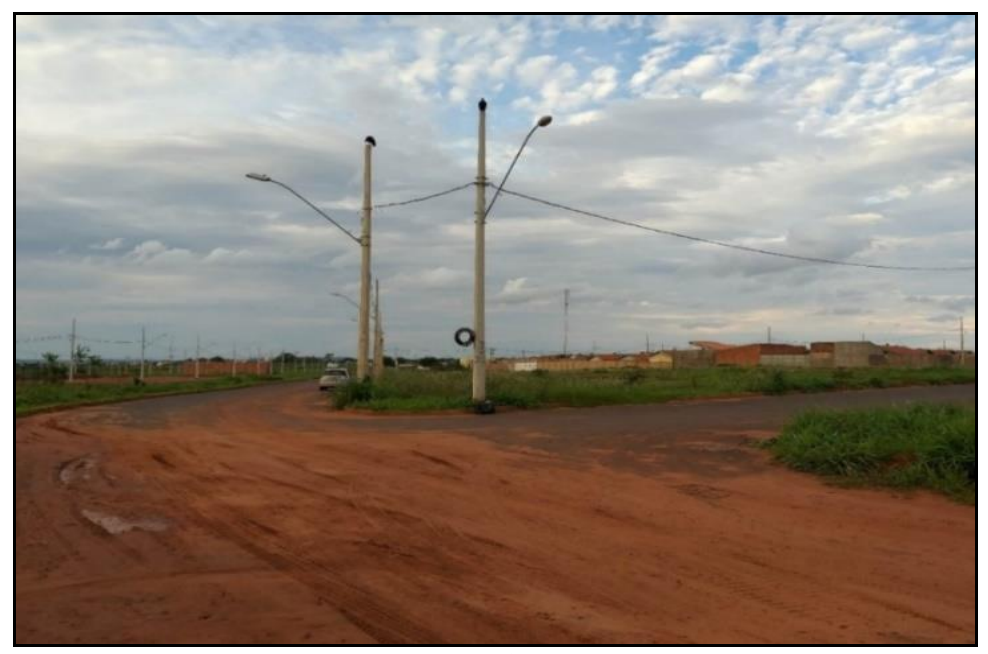

Fonte: BARBOSA, J.O 2018.

A acessibilidade é outro aspecto importante a ser mencionado, pois dado à sua localização, o bairro encontra-se numa localidade mais periférica da malha urbana e distante do centro da cidade. A linha de ônibus (via Ituiutaba Clube) passa entre intervalos de uma hora até uma hora e meia, e seu horário máximo é até as $21 \mathrm{~h} 00 \mathrm{~min}$, de tal maneira que se torna difícil deslocar-se para outras localidades da cidade.

As ruas são asfaltadas, porém, não há ciclovias ou rampas de acessibilidade nas esquinas e faixas de pedestres. Sobre iluminação, há postes de luz nos dois lados das ruas, no entanto, como não há domicílios ou outros bairros nas áreas próximas, a luz pública não é o suficiente para a iluminação adequada. Não foi encontrado em nenhuma das vias públicas do bairro lixeiras públicas de coleta seletiva.

Sobre o seu processo de construção e ocupação, o bairro Nova Ituiutaba I (Figuras 3 e 4) foi construído para atender à uma demanda habitacional, voltada para famílias que se enquadrassem na faixa 01 de financiamento, isto é, que a renda não ultrapasse de 1 a 3 salários-mínimos. Estes domicílios foram distribuídos a partir de um processo de seleção das condições socioeconômicas, coordenada pela Secretaria Municipal de Desenvolvimento Social de Ituiutaba, a partir de entrevistas e análise de documentos comprobatórios.

Figuras 3 e 4 - Ituiutaba/MG: representação das residências do bairro Nova Ituiutaba I nos modelos de conjunto habitacional, 2018.
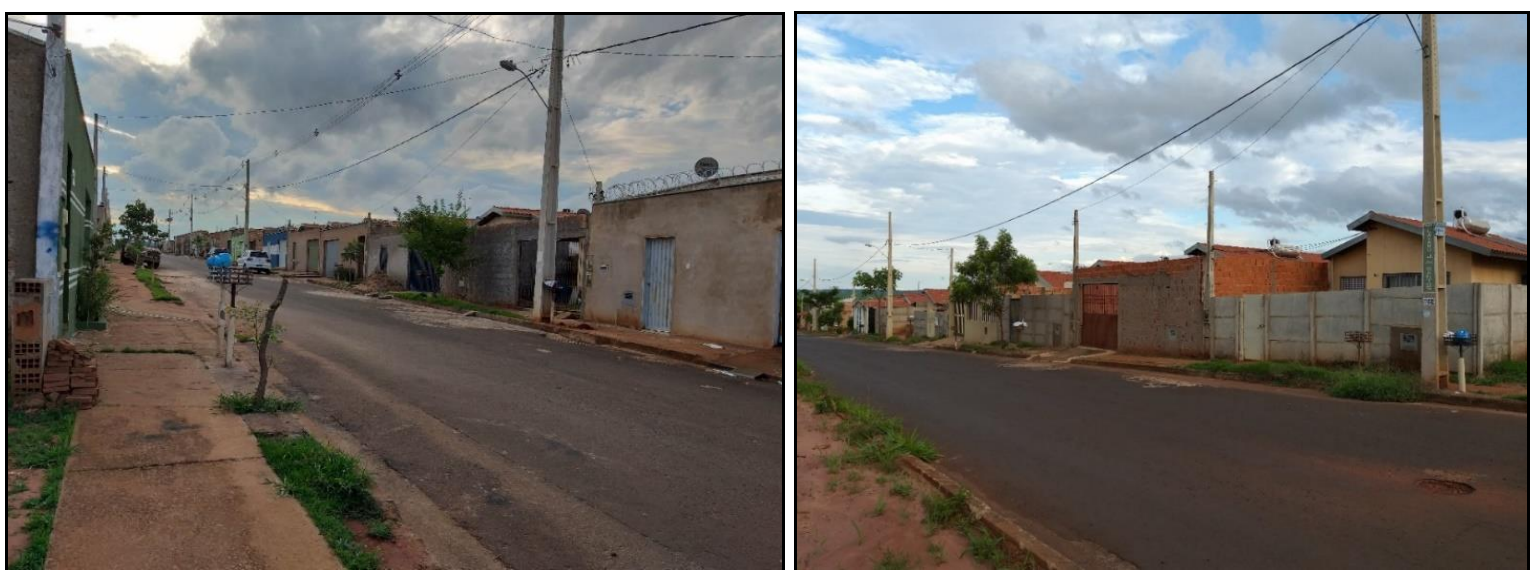

Fonte: BARBOSA, J.O, 2018. 
De acordo com o relatório do "Projeto de Trabalho Social do Residencial Nova Ituiutaba I", realizado pela Secretaria Municipal de Desenvolvimento Social de Ituiutaba, 97\% dos responsáveis pela unidade familiar são mulheres, a maioria (66\%) encontram-se na faixa etária de 24 a 44 anos, demonstrando que o bairro reflete os novos padrões familiares, com destaque para a representatividade feminina nas decisões e gestão familiar.

Nota-se que, do total de moradores, $70 \%$ é composto por crianças e adolescentes. Ao relacionarmos o tamanho da família, o relatório indica que $50,47 \%$ das famílias são compostas por duas pessoas, $21,93 \%$ por três pessoas e $19,47 \%$ por quatro pessoas, e $5,3 \%$ entre cinco e seis pessoas. Neste relatório é apontado também informações sobre escolaridade dos responsáveis pela unidade familiar.

A partir destes dados apresentados neste relatório, foi possível verificar que $54,82 \%$ dos responsáveis pelo domicílio não concluíram o ensino básico; destaca-se que, deste total, $40,45 \%$ não concluíram o ensino fundamental, $12,48 \%$ não concluíram o ensino médio e 1,89\% não foi alfabetizado. O percentual de responsáveis que tiveram acesso ao ensino superior completo é baixo, correspondendo a $4,73 \%$ da população residente. Assim, ao correlacionarmos estes dados, percebese que as mulheres responsáveis pelo domicílio não concluíram os estudos os estudos básicos.

Sobre as fontes de renda da família foi identificado que $76,37 \%$ dos responsáveis pelo domicílio trabalham, porém, somente $61,13 \%$ possuem carteira assinada; ao relacionarmos a renda, o relatório aponta que $38 \%$ das famílias vivem com um salário-mínimo e 58\% entre um e dois saláriosmínimos, e que somente 3,97\% possuem renda acima de dois salários- mínimos.

Com base nestas informações, percebe-se que o bairro é composto por um público com baixa escolaridade e renda. Ao relacionarmos os dados sobre a estrutura social dos moradores e as condições de infraestrutura, nota-se que o bairro apresenta carências e que a ideia de proporcionar moradia de qualidade e de superação das condições de pobreza não corresponde com a realidade. Estes aspectos demonstram as fragilidades sociais que a população vivencia e, por isso, torna-se relevante identificar a limpeza urbana como um dos serviços importantes não somente para proporcionar melhorias nas condições de qualidade ambiental do bairro, mas que contribua em maior conforto, saúde e segurança para a população.

Discutir, portanto, as condições de vida, a infraestrutura do bairro e o público que nele vivem permite compreender melhor os dados coletados e a realidade observada ao longo do trabalho de campo, a partir dos monitoramentos realizados. A seguir, será apresentado as etapas percorridas para a obtenção dos resultados e as impressões obtidas a partir das condições de limpeza urbana identificadas, de modo a representar seus possíveis impactos na qualidade ambiental.

O monitoramento de campo começou no dia 02 de setembro de 2017 e seria realizado aos sábados de manhã de cada semana até concluir a observação de todas as ruas. De acordo com as informações prestadas pelos moradores, a coleta de lixo no bairro ocorre três vezes na semana e é realizada nos dias de segunda-feira, quarta-feira e sexta-feira. $O$ objetivo inicial deste instrumento metodológico foi analisar, domicílio por domicílio, as condições de limpeza urbana (considerada, nesta pesquisa, enquanto a prestação de serviços de varrição de ruas, calçadas, poda de árvores, limpeza e manutenção de bueiros e capina de lotes vazios) nas calçadas, sarjeta, bueiros e lotes vazios, com base na existência (ou não) de resíduos depositados de forma inapropriada.

Dado o nível de detalhamento desta primeira etapa do monitoramento, o prazo de coleta estendeu-se até dezembro, pois além da demora em realizar a observação e o registro das informações encontradas, deu-se início ao período de chuvas de verão, o que dificultou a programação estabelecida. Diante deste contexto, ainda neste período de setembro a dezembro, notou-se que seria necessário alterar novamente a forma de coleta.

A coleta foi retomada nos meses de fevereiro e março, maio e junho e, dadas as poucas discrepâncias dos resultados encontradas em campo, as três amostras demonstraram ser suficientes para expressar as condições da limpeza urbana e seus impactos para a qualidade ambiental do bairro em questão. Entre a segunda e terceira etapa de observação, também foi realizada uma visita em campo para contabilizar, em cada rua, a quantidade de domicílios e de lixeiras domiciliares e lixeiras modelo de rua (em especial a de coleta seletiva).

Este procedimento teve como objetivo identificar se a quantidade de lixeiras domiciliares existente no conjunto corresponde ou não à quantidade de domicílios, a existência de lixeiras de rua nas vias

$\begin{array}{llllll}\text { Caminhos de Geografia } & \text { Uberlândia - MG } & \text { v. 21, n. } 73 & \text { Mar/2020 } & \text { p. 399-414 } & \text { Página } 406\end{array}$


públicas e em que medida a ausência de lixeiras pode potencializar o descarte inadequado de resíduos. A figura 5 a seguir apresenta as ruas que foram percorridas ao longo dos três monitoramentos realizados.

Figura 5 - Ituiutaba/MG: ruas percorridas nos monitoramentos de campo, entre os meses de setembro de 2017 a junho de 2018.

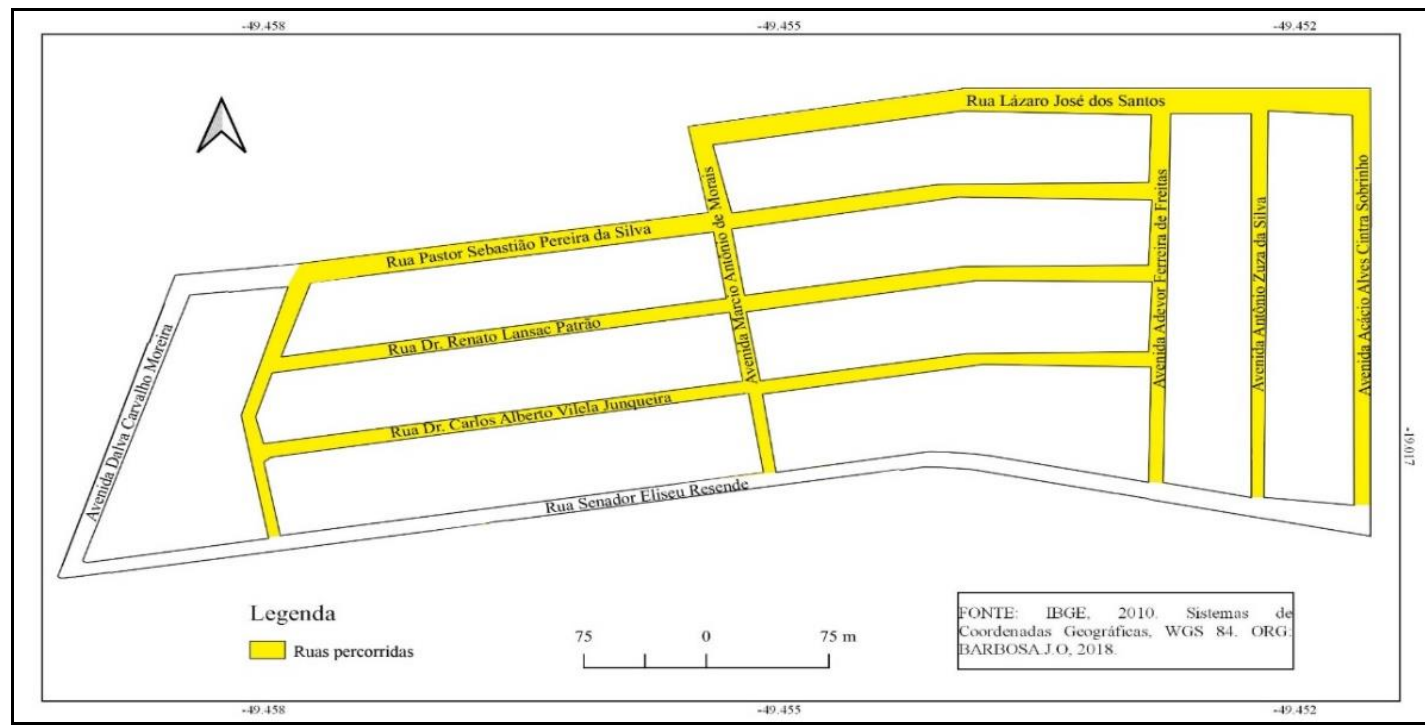

Fonte: Pesquisa direta, 2018

A respeito das ruas percorridas durante a coleta dos três monitoramentos é preciso esclarecer que a rua Senador Eliseu Resende e a avenida Dalva Carvalho Moreira não foram percorridas porque não há domicílios construídos em suas respectivas faces. Além disso, são locais que não possuem calçamento, impossibilitando a análise das condições de calçadas, conforme foi realizado com as demais ruas.

Figura 6 - Ituiutaba/MG: localização dos lotes vazios e bueiros identificados no bairro Nova Ituiutaba I, 2018.

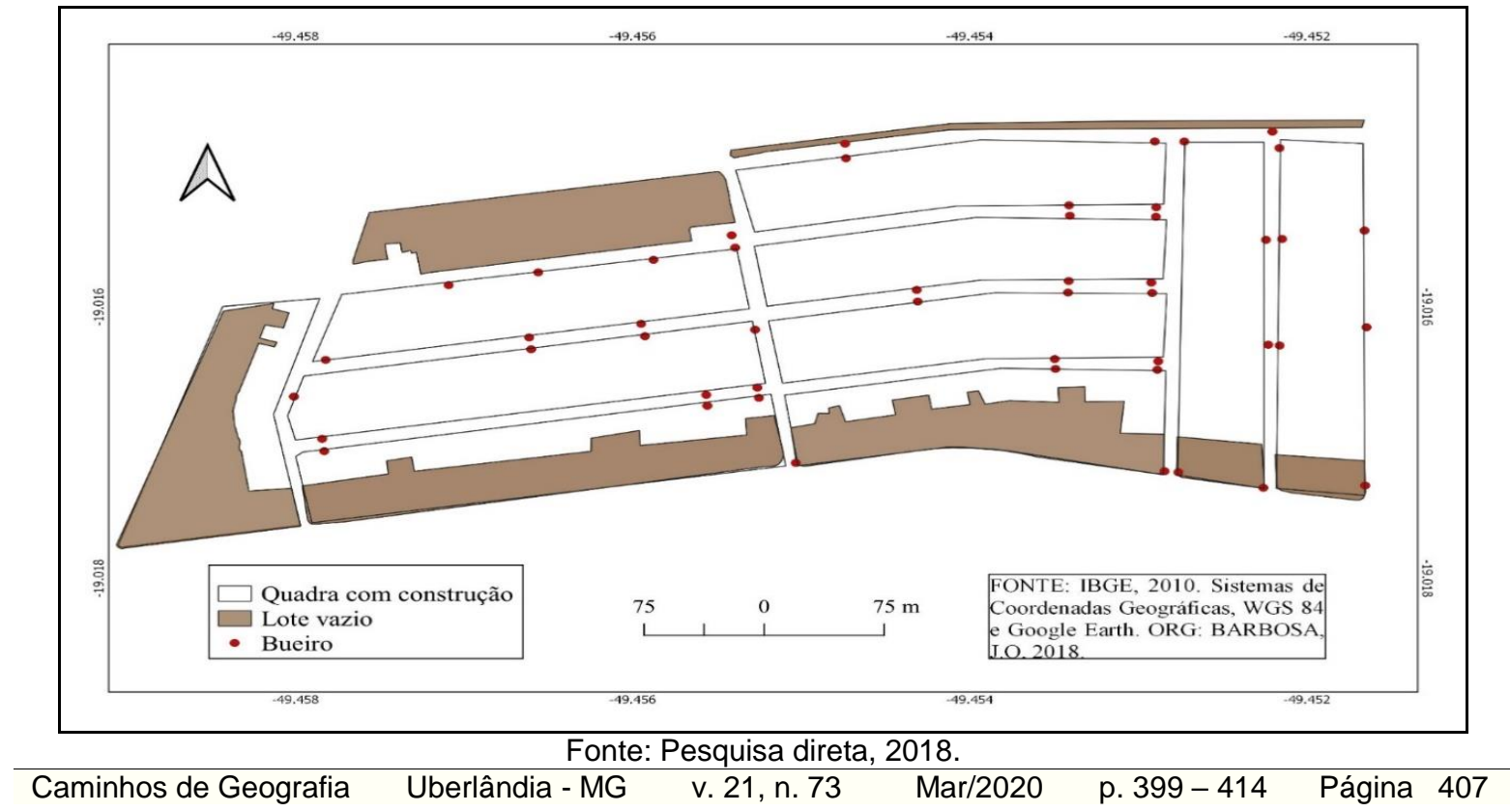


A localização dos bueiros nas ruas, aliada às informações obtidas a partir das observações, indica em que medida a emissão de resíduos dentro de bueiros pode comprometer a sua funcionalidade e eficiência, principalmente nos períodos chuvosos, representando a possibilidade de ocorrência de problemas para os moradores locais, como é o caso de entupimento, formação de pontos de alagamento, retorno do esgoto para os domicílios, dentre outros. A representação dos lotes e áreas vazias, (Figura 6) por sua vez, teve como objetivo apresentar a localização e tamanho destas áreas,

Inicialmente, os dados coletados foram transferidos para uma tabela, seguindo a ordem do próprio roteiro de observação. Ao analisar os resultados registrados no roteiro de observação, optou-se por sistematizá-los da seguinte forma: em cada monitoramento, elaborou-se uma tabela, na qual classificaram-se os itens identificados em categorias para melhor representação, dado a diversidade de elementos. Desta maneira, seria possível representá-los de forma mais homogênea. Optamos por classificá-los de acordo com a origem dos principais materiais e componentes que constituem os itens, conforme o Quadro 1.

Quadro 1 - Ituiutaba/MG: categorias e elementos encontrados nos monitoramentos, 2018.

\begin{tabular}{|c|c|}
\hline CATEGORIAS & TIPOS DE RESÍDUOS \\
\hline $\begin{array}{l}\text { CATEGORIA } 1 \\
\text { (PLÁSTICO) }\end{array}$ & $\begin{array}{c}\text { Copo plástico; Garrafa PET; } \\
\text { Embalagem ou rótulo de produtos alimentares, medicamentos e } \\
\text { cosméticos; Outros frascos de plástico; Plástico bolha; } \\
\text { Plástico de bala, chocolate, biscoito, salgadinho; } \\
\text { Sacola plástica com lixo; Sacola plástica vazia; }\end{array}$ \\
\hline CATEGORIA 2 (PAPEL) & $\begin{array}{c}\text { Caixa tetra pack; Bituca de cigarro; } \\
\text { Jornal; Papel; } \\
\text { Panfleto; Papelão; }\end{array}$ \\
\hline $\begin{array}{c}\text { CATEGORIA } 3 \text { (MATERIAL DE } \\
\text { CONSTRUÇÃO) }\end{array}$ & $\begin{array}{l}\text { Areia; Cimento; } \\
\text { Ferragem; Pedra; } \\
\text { Tijolo; }\end{array}$ \\
\hline $\begin{array}{c}\text { CATEGORIA } 4 \text { (MATERIAL } \\
\text { ORGÂNICO) }\end{array}$ & $\begin{array}{l}\text { Esgoto; Fezes de animais; } \\
\text { Folhas de árvores, mato; } \\
\text { Restos de alimentos; } \\
\end{array}$ \\
\hline $\begin{array}{c}\text { CATEGORIA } 5 \text { (MÓVEIS EM } \\
\text { DESUSO) }\end{array}$ & Móveis em desuso; Eletrodomésticos em desuso; \\
\hline CATEGORIA 6 (OUTROS) & Latinha de alumínio; Vidro. \\
\hline
\end{tabular}

Ressalta-se que estes itens que compõe as seis categorias foram escolhidos a partir de visitas prévias antes da realização do trabalho de campo, nos quais estavam presentes nas calçadas, sarjetas e nos lotes vazios. Considerou-se que, independentemente da quantidade de cada um destes, o fato de estarem presentes nas calçadas, sarjetas e lotes vazios seria o suficiente para caracterizar o descarte inadequado.

Destaca-se que nos resultados obtidos nos três monitoramentos, é possível tecer algumas considerações acerca das condições de limpeza urbana e, de que maneira estes resíduos depositados inadequadamente podem comprometer a qualidade ambiental. A primeira constatação é que o serviço de limpeza urbana não ocorre com a frequência necessária e nem de forma adequada, tendo em vista que, se o mesmo fosse realizado, não haveria tantos resíduos depositados nas calçadas, sarjetas e lotes vazios.

A figura 7 apresenta os itens que registraram maior quantidade de ocorrências ao longo dos três monitoramentos realizados nas calçadas, sarjetas e lotes vazios; para a elaboração deste gráfico, consideraram-se os elementos que apareceram nos três monitoramentos em cada um dos pontos observados (isto é, calçadas, sarjetas e lotes vazios), e em mais da metade do total de ruas percorridas.

$\begin{array}{llllll}\text { Caminhos de Geografia } & \text { Uberlândia - MG } & \text { v. 21, n. } 73 & \text { Mar/2020 } & \text { p. } 399-414 & \text { Página } 408\end{array}$


Com base nestes dados, conclui-se, portanto, que a maior parte dos itens descartados nas calçadas, sarjetas e lotes vazios estão relacionados à materiais de consumo imediato (bituca de cigarro, panfleto, plástico de bala, chocolate, biscoito, salgadinho, papel, sacola plástica vazia), materiais de construção (areia, cimento, pedra, tijolo) e de material orgânico (folhas de árvores/mato). Além disso, ao analisarmos os tipos de resíduos encontrados nos Monitoramento s 1, 2 e 3, percebe-se alguns aspectos importantes, tais como:

Figura 7 - Ituiutaba/MG: média dos principais itens descartados nos monitoramentos 01, 02 e 03 , 2018.

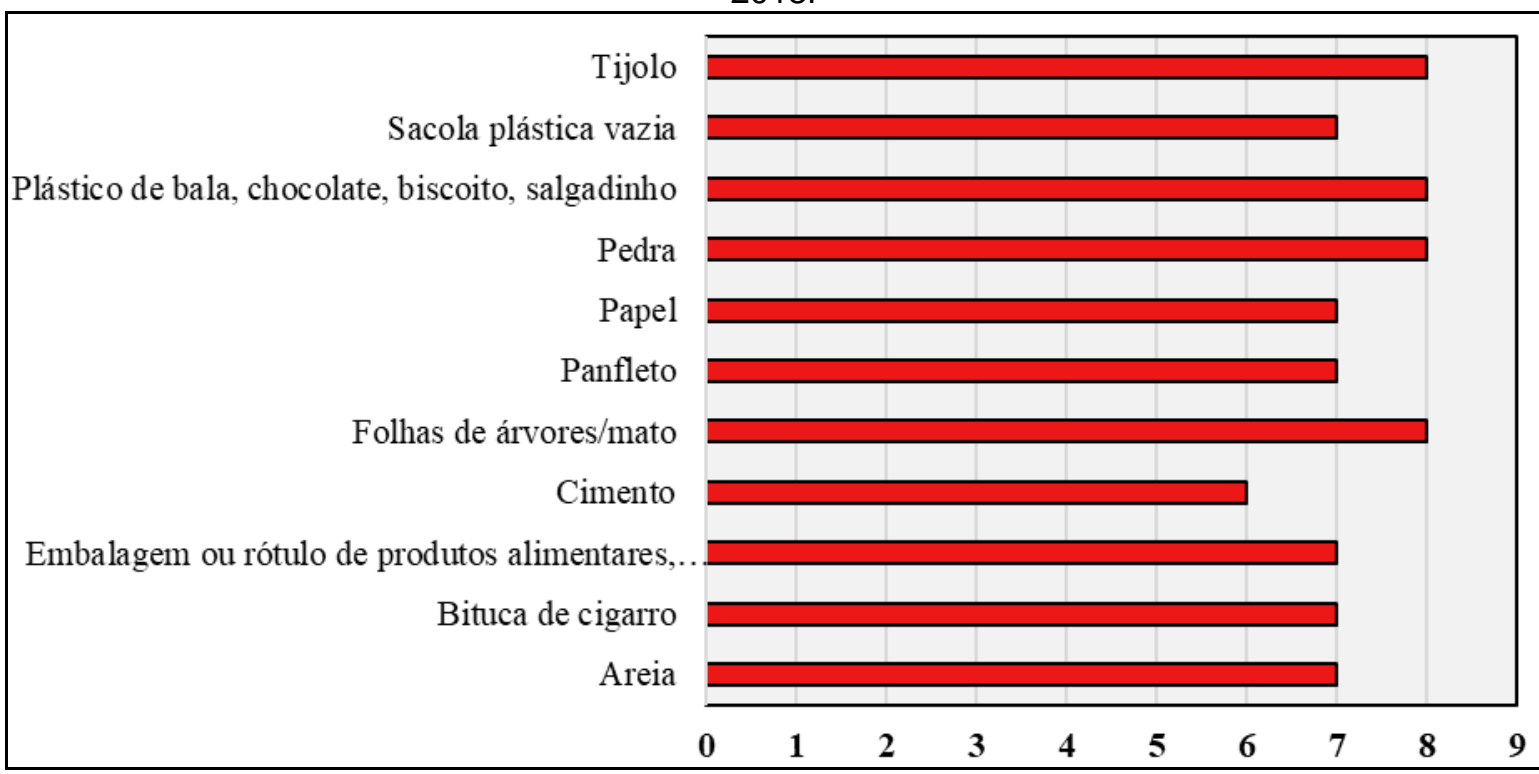

Fonte: Pesquisa direta, 2018.

- A partir dos elementos identificados, entende-se que itens como bituca de cigarro, plásticos de bala, chocolate, biscoito, salgadinho, panfleto são tipos de resíduos de consumo imediato e que demonstra que a população consome os produtos e os descarta principalmente nas calçadas e sarjetas. Como não foi encontrada nenhuma lixeira pública de rua, inclusive as de coleta seletiva, trata-se de um aspecto que contribui significativamente para estes resultados obtidos. Estes resíduos oferecem riscos ao funcionamento dos bueiros, principalmente nos períodos de chuva;

- Itens como embalagens e/ou rótulos de produtos alimentares, garrafa pet, sacola plástica com lixo, sacola plástica vazia, papel pode ser descartados adequadamente nas lixeiras domiciliares ou nas lixeiras coletivas (porém, o bairro não possui nenhuma lixeira de descarte coletivo). $O$ fato de encontrarmos este tipo de resíduo descartado nas calçadas indica que, além da limpeza não ser realizada de forma frequente, o sistema de coleta de lixo não recolhe resíduos que não estejam dispostos dentro dos sacos plásticos. Este tipo de descarte pode ter sido feito de forma proposital ou acidental (isto é, os sacos de lixo foram rasgados por animais, pessoas, ou simplesmente não suportaram o volume de lixo armazenado).

- Além de prejudicar os bueiros das ruas e provocar pontos de alagamento, estes tipos de resíduos podem se tornar focos de insetos vetores de doenças, tais como mosquitos (destaca-se o Aedes aegypti, transmissor de doença como a dengue, febre amarela, chikungunya), escorpião, mosca, barata. O item sacola plástica com lixo, mesmo que em menores proporções, representam risco, pois além de provocar os problemas descritos acima, os animais domésticos de rua podem rasgálos, sujando as vias públicas e provocando mau cheiro. (Figura 8)

- O descarte de restos de alimentos pode atrair, por exemplo, animais como pombos e ratos e vetores de doenças graves (dermatites, salmonela, leptospirose, dentre outros). O mesmo ocorre

$\begin{array}{llllll}\text { Caminhos de Geografia } & \text { Uberlândia - MG } & \text { v. 21, n. } 73 & \text { Mar/2020 } & \text { p. 399-414 Página } 409\end{array}$


com a falta de limpeza de fezes de animais, que podem ser altamente perigosas à saúde da população por transmitir vírus e bactérias, como adenovírus, parvovirus, giárdia, dentre outros;

Figura 8 - Ituiutaba/MG: tipos de resíduos encontrados nos lotes vazios do bairro Nova Ituiutaba I, 2018.

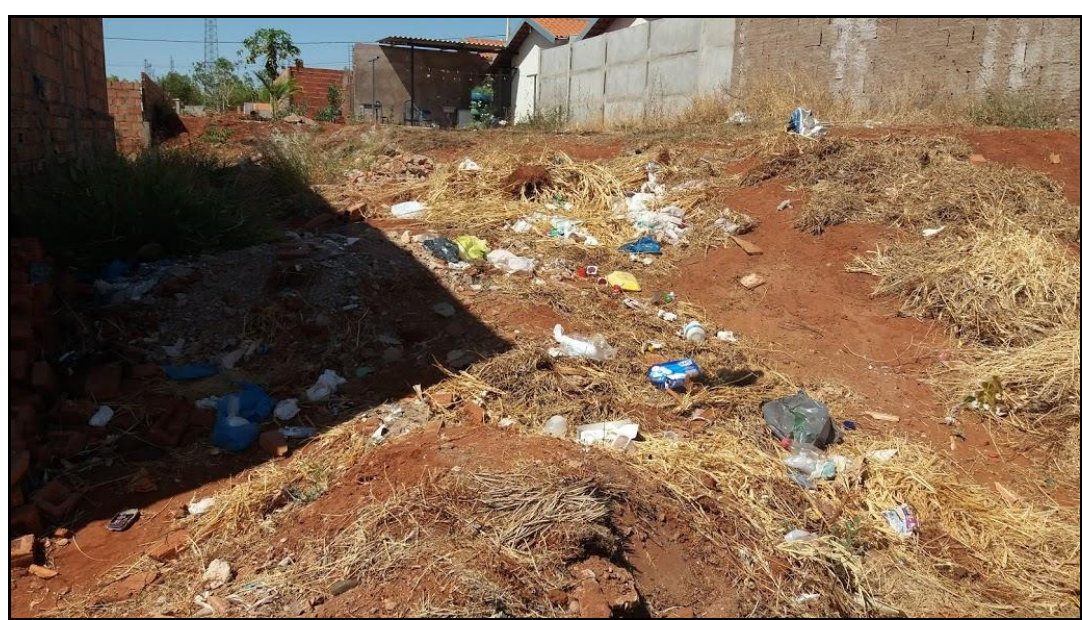

Fonte: AUTOR, 2018.

- Os itens relacionados a material de construção (ver Figura 9), tais como areia, cimento, pedra e tijolo indica alguns fatores interessantes: as casas construídas pelo Programa Minha Casa Minha Vida são entregues sem muros, lavanderia, sem garagem ou área de lazer, sem piso externo. Dessa maneira, muitos moradores realizam reformas para ampliar ou melhorar as condições do domicílio. Dado à falta de fiscalização, estes materiais são depositados nas calçadas e, por vezes, ao longo ou no final da obra, os restos de demolição ou dos próprios materiais são descartados em lotes vazios ou nas calçadas (Figura 9).

Figura 9 - Ituiutaba/MG: resíduos de material de construção depositado nas calçadas do bairro Nova Ituiutaba I, 2018.

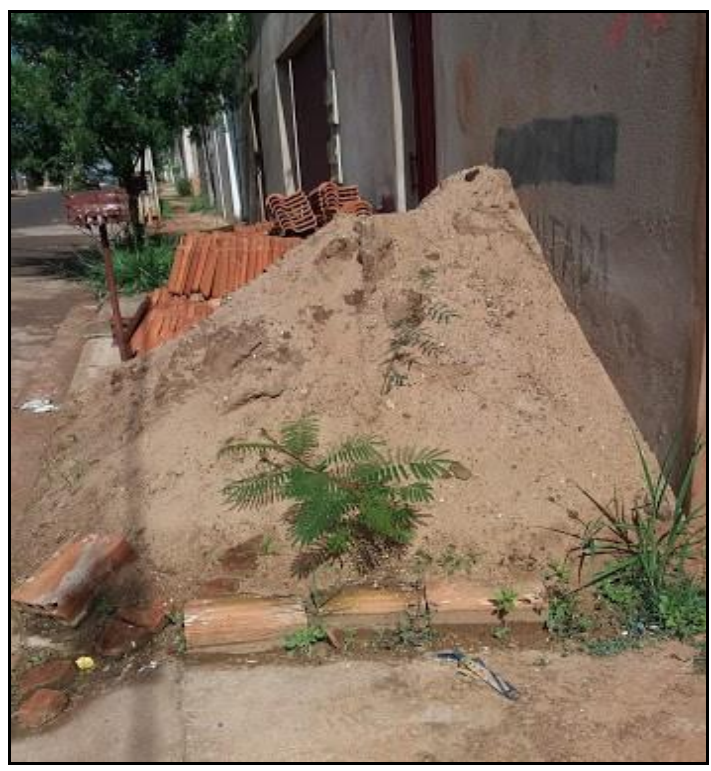

Fonte: AUTOR, 2018

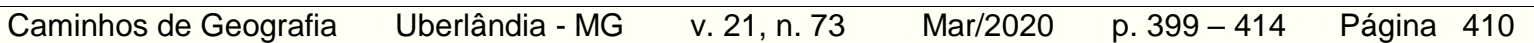


Além de sujar as ruas, estes materiais impedem a passagem de pedestres nas calçadas e prejudicando a acessibilidade das mesmas. No caso do item tijolo, que também atrapalha a circulação de pessoas, torna-se foco de insetos como barata, aranhas, escorpião, que podem colocar em risco a saúde da população. No caso da areia e pedra, quando depositado nas calçadas, podem ser levados pelas chuvas para as ruas, podendo prejudicar a circulação de ciclistas e motociclistas, além de entupir os bueiros. Já o item ferragem, apesar de ter apresentado baixa ocorrência ao longo dos monitoramentos, pode representar um sério risco à saúde da população, pois além de provocar machucados, este pode causar doenças como o tétano, dado a oxidação do material.

- Folhas de árvores (ver Figura 7) não provocam problemas para a população, entretanto, quando não recolhidas, ao serem carregadas pela chuva e ventos para podem provocar entupimento dos bueiros;

- Alguns itens como caixa tetra pack, papelão, latinha de alumínio, garrafa pet são vendidos no mercado de reciclados, por isso apresentaram menor quantidade de ocorrência de descarte. Mesmo assim, trata-se de resíduos que poderiam ser descartados nas lixeiras seletivas, caso o bairro dispusesse de alguma, ou em caçambas coletivas. É importante lembrar que estes materiais são recicláveis e, se descartados adequadamente pode, a partir do processo de reciclagem, ser reaproveitados e dar origem a outros produtos, fortalecendo o mercado de produtos sustentáveis;

- Apesar de ter sido encontrado em pequenas proporções, o item vidro apresenta alto risco para a população, uma vez que, como o bairro não dispõe de áreas de lazer e um dos maiores públicos é o infantil, a disposição destes nas calçadas, sarjetas e terrenos vazios pode se tornar perigoso para as crianças que costumam brincar ou passar o tempo na rua;

- O item eletrodoméstico em desuso, encontrado nas calçadas, sarjetas e lotes vazios, podem oferecer riscos à saúde da população e ao ambiente, pois muitos são compostos por gases químicos, tais como clorofluorcarbono - CFC, além de componentes químicos, como, por exemplo, chumbo, mercúrio, cádmio, que estão presentes, por exemplo, em televisores, celulares, computadores. Trata-se de resíduos que podem ter a destinação adequada, mas que, dado à falta de limpeza nas ruas e de fiscalização - principalmente em caso de descartes em lotes vazios - a pequena colaboração da população em preservar as condições adequadas de limpeza das calçadas, sarjetas e lotes vazios, aliado à falta de programas e projetos de educação ambiental para os moradores, acabam por prejudicar as condições de qualidade ambiental (Figura 10).

Figura 10 - Ituiutaba/MG: eletrodomésticos descartados em lotes vazios do bairro Nova Ituiutaba I, 2018.

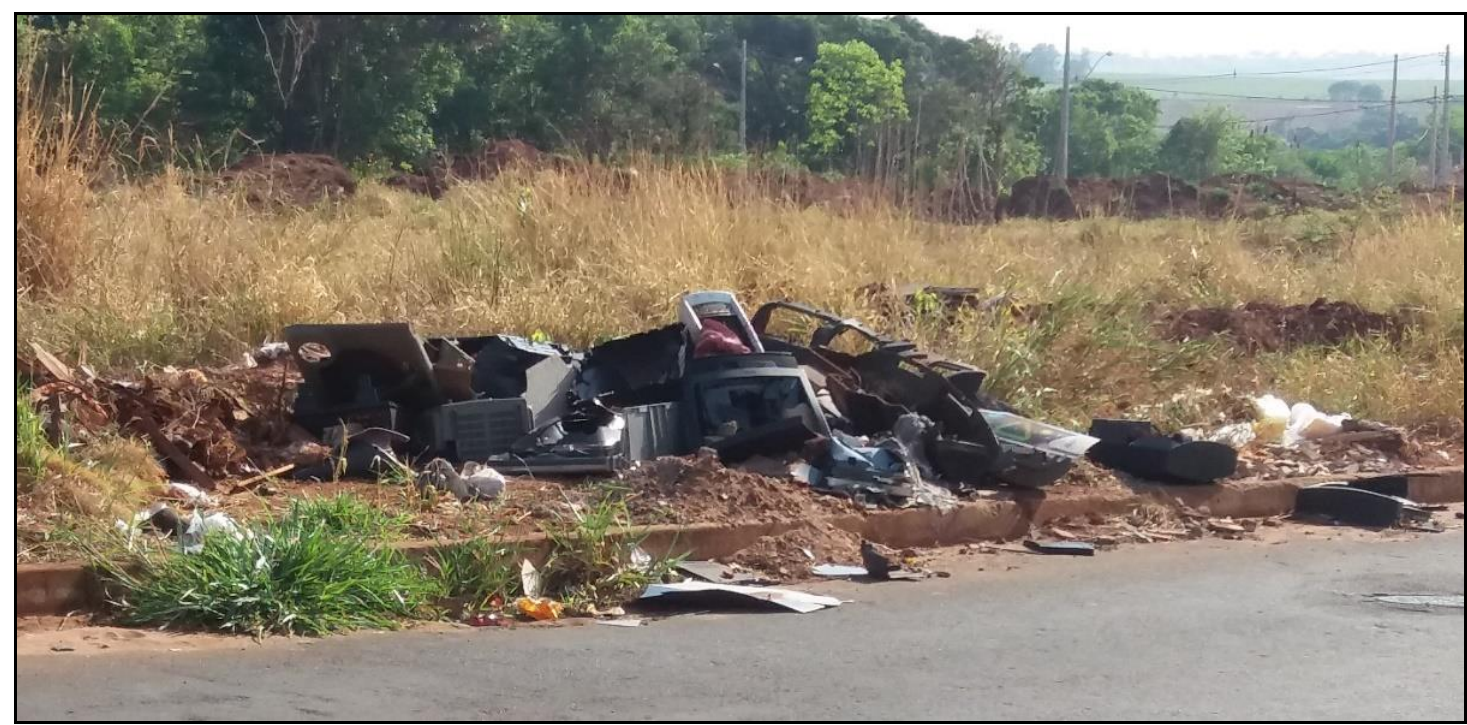

Fonte: AUTOR, 2018.

$\begin{array}{llllll}\text { Caminhos de Geografia } & \text { Uberlândia - MG } & \text { v. 21, n. 73 } & \text { Mar/2020 } & \text { p. 399-414 } & \text { Página } 411\end{array}$


Já os móveis em desuso, quando descartados em calçadas e lotes vazios, podem tornar-se foco de insetos peçonhentos e vetores de doenças. Muitas vezes, a própria população, além de descartar este tipo de material, acaba ateando fogo, como forma de descartá-lo totalmente. Esta prática representa risco de incêndio, além de provocar sujeira nas ruas, calçadas e domicílios e pode provocar problemas para a saúde da população devido à fumaça.

Além do levantamento das condições de limpeza nas calçadas, sarjetas e lotes vazios, foram verificadas também as condições dos bueiros nos três monitoramentos, observando-se havia depósito de resíduos em suas grades e, principalmente, no seu espaço interior, identificando os diferentes tipos de resíduos existentes.

A partir das observações realizadas, verificou-se que $85 \%$ destes bueiros encontravam-se sujos, com mais de três tipos de resíduos, com base nos itens das categorias estabelecidas. Como os tipos de resíduos eram variados, não foi possível estabelecer um padrão ou mesmo quantificá-los. Notou-se, porém, que existem alguns itens que se tratam de resíduos oriundos de consumo imediato, como copo plástico, sacola plástica vazia, embalagem de salgadinho, embalagem de produtos alimentícios, papel. Estes itens, portanto, colaboram significativamente para formação de pontos de alagamentos em períodos chuvosos.

Outros itens também foram encontrados dentro dos bueiros, tais como roda de bicicleta, fiação, roupas, restos de massa de cimento, cabo de vassoura e até mesmo uma escada. Trata-se de materiais e resíduos que devem ser descartados de outras formas, a partir da coleta seletiva ou da contratação de empresas de aluguel de caçambas. Estes materiais, portanto, inviabilizam o desempenho dos bueiros.

Com base nos resultados obtidos e analisados, observa-se o quanto a limpeza urbana neste bairro trata-se de um serviço importante e indispensável. Os tipos de resíduos encontrados demonstram alguns aspectos que são pertinentes, como é o caso dos resíduos de consumo imediato, os resíduos oriundos de atividades de construção e os resíduos domiciliares descartados nos lotes vazios.

\section{AGRADECIMENTOS}

Agradecemos à Fundação de Amparo à Pesquisa do Estado de Minas Gerais (FAPEMIG), pelo auxílio financeiro ofertado pela de bolsa de mestrado, ao longo de quatro meses no ano de 2017, e à Prefeitura Municipal de Ituiutaba - MG pelos dados fornecidos acerca do Bairro Nova Ituiutaba I.

\section{CONSIDERAÇÕES FINAIS}

Os resíduos que foram encontrados, em maiores ou menores quantidades, representam diferentes tipos de riscos e periculosidade, tanto para a saúde da população, quanto para a qualidade ambiental, uma vez que o descarte inadequado pode provocar, a curto, médio, e longo prazo, problemas ambientais, tais como poluição (inclusive visual), contaminação do solo (mesmo que seja de pequeno impacto), pontos de alagamento, mau-cheiro, aumento da população de insetos peçonhentos e vetores de doenças.

O serviço de limpeza urbana demonstrou ser ineficiente, dado as condições de limpeza encontrado nos bairros. A ausência de lixeiras nos bairros, a falta de fiscalização perante o descarte em lotes vazios e o frequente depósito de resíduos de materiais de construção nas calçadas, lotes vazios e sarjetas tratam-se de problemas que comprometem a limpeza urbana no bairro.

Além disso, a população não colabora com a melhoria das condições de limpeza urbana, ao descartarem desde resíduos de origem doméstica (como por exemplo, sacos plásticos com lixo, restos de alimentos) até móveis e eletrodomésticos em desuso. Isso demonstra a falta de sensibilização ambiental, oriunda da ausência de educação ambiental.

A limpeza urbana, portanto, pode ser entendida como um indicador importante da qualidade ambiental urbana; este serviço, quando ofertado da forma correta e apoiado a partir da colaboração da população, pode diminuir potencialmente os problemas que colocam em risco as condições ideais e adequadas de qualidade ambiental. Ressalta-se, porém, que a limpeza urbana é apenas um dos múltiplos indicadores da qualidade ambiental, uma vez que, para a sua avaliação, é importante considerarmos os demais indicadores, tais como a poluição, áreas verdes, saneamento básico, condições do solo, uso e ocupação do solo, dentre outros.

$\begin{array}{llllll}\text { Caminhos de Geografia } & \text { Uberlândia - MG } & \text { v. 21, n. 73 } & \text { Mar/2020 } & \text { p. 399-414 Página } 412\end{array}$


A Prefeitura Municipal possui grande responsabilidade perante esta situação, uma vez que, além de não haver legislação municipal específica sobre limpeza urbana, não existe nenhum instrumento de controle e fiscalização de descarte inadequado de resíduos sólidos. Isso reforça o posicionamento de descaso do poder público municipal perante a questão da limpeza urbana.

Além disso, alguns instrumentos, que deveriam ser obrigatórios no bairro, tais como lixeiras públicas seletivas, caçambas coletivas, por exemplo, simplesmente não existem. A limpeza urbana não é realizada semanalmente e não há serviço de limpeza e manutenção dos bueiros e lotes vazios. A falta de coleta seletiva de resíduos ocasionada pela falta de iniciativa da população em separar os seus resíduos já indica o quão preocupante é a situação do gerenciamento de resíduos e, consequentemente, das condições de limpeza urbana. Portanto, todos estes aspectos colaboram para a atual situação da limpeza urbana no bairro.

Percebe-se também que o poder municipal não promove atividades e projetos de longa duração voltados para a Educação Ambiental no bairro, que tem um papel fundamental neste caso, pois sensibilizaria a população a realizar o descarte de qualquer tipo de resíduo da forma adequada. Além de ensinar a importância da conservação dos espaços públicos, a Educação Ambiental alertaria aos moradores de que maneira o descarte inadequado de resíduos pode colocar em risco a saúde e o ambiente e, ao mesmo tempo, mostrar o quão a limpeza urbana proporciona melhorias para o ambiente e sociedade.

O projeto do PMCMV é oferecer moradias populares à população de baixa renda, como uma das estratégias de redução das condições de pobreza. Todavia, não basta apenas oferecer um teto para a população. A pobreza não se limita à fome ou falta de lugar para viver. A pobreza refere-se também a privação dos serviços básicos e condições saudáveis de habitar; isso inclui, portanto, o acesso a moradia de qualidade, em um ambiente limpo, saudável, e que não coloque em risco as condições ambientais.

Salienta-se que a Geografia e demais ciências ligadas ao planejamento e gestão do espaço urbano podem ampliar os estudos desta temática, identificando a limpeza urbana enquanto um serviço essencial para a qualidade ambiental e de vida da população. Além disso, esta temática pode contribuir para os estudos dos programas habitacionais de interesse social, de modo a oferecer uma base teórica e metodológica para a realização de projetos e ações que proporcionem melhoras para as condições ambientais e de habitação.

Percebe-se, neste sentido, que o planejamento do bairro Nova Ituiutaba I garantiu apenas o acesso à moradia, porém, as condições de habitação não são as adequadas para garantir o habitar de forma saudável e segura ambientalmente. A limpeza urbana, neste sentido, não apenas indica os problemas existentes, mas é uma das soluções dos problemas existentes, e que pode contribuir potencialmente para a construção de um bairro que ofereça melhores condições de vida a população, apoiado em um ambiente equilibrado e seguro.

\section{REFERÊNCIAS}

ANDRADE, Maria Maria de. Introdução à Metodologia do Trabalho Científico. 10. ed. São Paulo: Atlas, 2010.

ASSOCIAÇÃO BRASILEIRA DE LIMPEZA URBANA. Índice de Sustentabilidade de Limpeza Urbana para os municípios brasileiros. 2014.

BARBOSA, J.O. Limpeza Urbana e Qualidade Ambiental no Bairro Nova Ituiutaba na cidade de Ituiutaba / MG. 2018. Dissertação (Mestrado em Geografia) Programa de Pós-Graduação em Geografia do Pontal (PPGEP). Universidade Federal de Uberlândia. 171 p.

CÂMARA MUNICIPAL DE ITUIUTABA. Lei n.o 7.099 de 15 de Março de 2012. Institui o Loteamento Nova Ituiutaba I enquanto bairro. Ituiutaba - MG. Prefeitura Municipal de Ituiutaba: Ituiutaba, 2012.

DEMO, Pedro. Metodologia Científica em Ciências Sociais. 3. ed. rev. ampl. São Paulo: Atlas, 1995.

\begin{tabular}{|c|c|}
\hline de Ge & Uberlândia - MG \\
\hline
\end{tabular}


FERREIRA, Leilaine de Fátima. Qualidade ambiental nas habitações de interesse social nos bairros Sol Nascente e Canaã II em Ituiutaba. 2016. 196 f. Dissertação (Mestrado em Geografia) Instituto de Geografia, Universidade Federal de Uberlândia, Uberlândia, 2016.

GODOY, Samuel Ralize de. Muito além da lata de lixo: a construção da política pública e a organização do mercado de limpeza urbana no município de São Paulo. 2015. 146 f. Dissertação (Mestrado em Ciência Política) - Departamento de Ciência Política da Faculdade de Filosofia, Letras e Ciências Humanas, Universidade de São Paulo, São Paulo, 2015.

INSTITUTO BRASILEIRO DE GEOGRAFIA E ESTATístICA (IBGE). Pesquisa Nacional de
Saneamento Básico 2008. Rio de Janeiro: 2010. Disponível em: <https://biblioteca.ibge.gov.br/visualizacao/lgrossovros/liv45351.pdf>. Acesso em: 10 jan. 2018.

LIMA, Valéria; AMORIM, Margaret Cristiane da Costa Trindade. Qualidade ambiental urbana em Oswaldo Cruz/SP. In: SIMPÓSIO BRASILEIRO DE GEOGRAFIA FÍSICA APLICADA, 13., 2009. Viçosa-MG. Anais... Viçosa-MG: UFV, 2009. Disponível em: <www.geo.ufv.br/ simposio/simposio/trabalhos/trabalhos completos>. Acesso em: 10 abr. 2016.

LIMA, Valéria. A sociedade e a natureza na paisagem urbana: análise de indicadores para avaliar a qualidade ambiental. 2013. 359 f. Tese (Doutorado em Geografia) - Universidade Estadual Paulista, $\begin{array}{lll}\text { Presidente } \quad \text { Prudente, } & 2013 . & \text { Disponível } \\ & & \end{array}$ <http://www.2.fct.unesp.br/gep/dis_teses/13/dr/valeria.pdf>. Acesso em: 26 ago. 2016.

MINAKI, Cíntia. O clima urbano como indicador de qualidade ambiental: estudo de caso da paisagem urbana de Araçatuba/SP. 2014. 266 f. Tese (Doutorado) - Faculdade de Ciências e Tecnologia de Presidente Prudente, Universidade Estadual Paulista, Presidente Prudente, 2014.

NUCCI, João Carlos. Qualidade Ambiental e Adensamento Urbano: um estudo de Ecologia e Planejamento da Paisagem aplicado ao distrito de Santa Cecília (MSP). 2. ed. Curitiba, 2008, p. 158.

REIS, João Paulo Alves dos; FERREIRA, Osmar Mendes. Aspectos sanitários relacionados à apresentação do lixo urbano para coleta pública. Goiânia, dezembro de 2008. Disponível em: $<$ http://www.pucgoias.edu.br/ucg/prope/cpgss/ArquivosUpload/36/file/>. Acesso em: 20 maio 2017.

Recebido em: 11/05/2019

Aceito para publicação em: 21/08/2019 